Title Page

\title{
Assessment of chronic illness-related cognitive fusion: \\ Preliminary development and validation of a new scale with an IBD sample
}

Inês A. Trindade, MSc, PhD student $1 *$

Cláudia Ferreira, $\mathrm{PhD}^{1}$

José Pinto-Gouveia, MD, $\mathrm{PhD}^{1}$

${ }^{1}$ CINEICC - Cognitive and Behavioural Centre for Research and Intervention Faculty of Psychology and Educational Sciences

University of Coimbra, Portugal

* Correspondence concerning this article should be addressed to:

Inês A. Trindade

Email: almeidatrindade@fpce.uc.pt

CINEICC, Faculdade de Psicologia e Ciências da Educação,

Universidade de Coimbra

Rua do Colégio Novo, Apartado 6153

3001-802 Coimbra, Portugal

Telephone: (+351) 239851450

Fax: (+351) 23985146 


\title{
Assessment of chronic illness-related cognitive fusion: \\ Preliminary development and validation of a new scale with an IBD sample
}

\begin{abstract}
Although research recognizes the advantages of creating specific content measures, no specific measure of chronic illness-related cognitive fusion had been developed to date. The current study presents the development and validation of the Cognitive Fusion Questionnaire-Chronic Illness (CFQ-CI) in a sample of inflammatory bowel disease (IBD) patients and the analysis of the role of this construct in the psychological health of those patients. Results indicated that the 7-item CFQCI was a unidimensional measure of cognitive fusion in patients with chronic illnesses, and that scores had adequate/good internal consistency and construct, convergent, and discriminant validity. This study also showed that chronic illness-related cognitive fusion as assessed by the CFQ-CI acted as a mediator in the association between both IBD-related symptoms and shame with quality of life. The development of the CFQ-CI may thus contribute to a better understanding of the mechanisms influencing functional outcomes in chronic illness.
\end{abstract}

Keywords: Chronic illness; Acceptance and commitment therapy; Cognitive fusion; Emotion regulation; Measurement. 


\section{Introduction}

In modern industrialized countries, chronic illnesses affect almost half of the adult population (Ward, Schiller, \& Goodman, 2014). Chronic illness has been in fact considered a main public health issue, significantly affecting individuals, their families, communities, and economic welfare (Gerteis et al., 2014). Extensive literature has indicated that having one or more chronic health conditions is a risk factor for reduced well-being and for developing an anxiety or depressive disorder (e.g. Clarke \& Currie, 2009). It is also known that chronic illness may affect psychological factors and daily life behaviours to an extent that can impact somatic symptomatology, disease course, and prognosis (e.g. Levenstein, 2004). Recent research has therefore increasingly focused on factors beyond direct symptom reduction that may influence functional outcomes in a variety of chronic illnesses (McCracken, 2011). A large number of these studies have been based on Acceptance and Commitment Therapy (ACT; Hayes, Strosahl, \& Wilson, 2012), one of the most representative therapies of behaviour therapy's third wave.

ACT conceptualizes psychological suffering as a main result from the emotion regulation processes one uses to deal with unwanted experiences, as opposed to those experiences themselves (Segal, Williams, \& Teasdale, 2002). ACT thus considers psychological suffering a product of psychological inflexibility defined as the unwillingness to accept unwanted internal experiences (such as negative sensations, thoughts, or emotions), even when doing so holds the individual back from meeting important values or life directions (Hayes, Luoma, Bond, Masuda, \& Lillis, 2006). Cognitive fusion is considered to be one of the core human experiences that contributes to psychological inflexibility, being often described as the tendency to regard thoughts as literal representations of reality and to get entangled with their verbal content (e.g. Gillanders et al., 2014). Thoughts are thus considered objective and permanent events in 
the mind that are experienced as true descriptions of reality rather than transitory and normative human experiences. This process often triggers emotional responses to unwanted cognitions and efforts to avoid contact with certain thoughts (Hayes et al., 2006). As a result, these patterns of entanglement and control tend to make behaviour overly regulated by internal events, restraining and limiting one's behavioural repertoire (Hayes et al., 2006). Individuals highly engaged in cognitive fusion thus usually disregard contextual contingences and chosen life values in efforts to control or avoid unwanted internal experiences (Hayes et al., 2006, 2012). For example, in chronic illness, patients may avoid going to medical appointments or taking prescribed medication to avoid unpleasant experiences (e.g. additional diagnoses; unwanted side-effects of medication) (e.g. Hadlandsmyth, White, Nesin, \& Greco, 2013). In addition, fusion with illnessrelated pain and attempts to avoid it usually aggravate its impact and may restrict the patient's willingness to perform valued life activities that may induce pain (Vlaeyen \& Linton, 2000). In inflammatory bowel disease (IBD), an autoimmune chronic condition with severe symptomatology such as urgent diarrhoea, faecal incontinence, gas, abdominal pain, and extreme fatigue, for example, patients may also get fused with their symptoms and illness and avoid work or social situations where their symptomatology may be perceived by others as embarrassing (Trindade, Ferreira, \& Pinto-Gouveia, 2017a, 2017b). IBD patients' psychosocial functioning is in fact usually significantly impaired due to the illness itself (e.g. Graff et al., 2006) and the emotion regulation processes involved (Trindade, Ferreira, \& Pinto-Gouveia, 2015a, 2015b, 2017a, 2017b).

ACT does not promote the modification or elimination of difficult internal events and does not look for a direct reduction of pain or discomfort; ACT rather focuses on promoting more adaptive ways of regulating internal experiences (Hayes et al., 2012). ACT aims to develop psychological flexibility, i.e. "the ability to contact the present 
moment more fully as a conscious human being, and to change or persist in behaviour when doing so serves valued ends" (Hayes et al., 2006, p. 8). ACT interventions have been found to present positive outcomes in a variety of chronic health conditions. Several randomized controlled studies have provided favourable empirical evidence for ACT in chronic pain (e.g. Vowles \& McCracken, 2008), cancer (e.g. Branstetter, Wilson, Hilderbrandt, \& Mutch, 2004), epilepsy (Lundgren, Dahl, Melin, \& Kies, 2006), and diabetes (Gregg, Callaghan, Hayes, \& Glenn-Lawson, 2007). Furthermore, the ACT model has also received support from research highlighting the role of psychological inflexibility over different types of symptoms and psychological constructs (e.g. depression, anxiety, substance abuse) in numerous longitudinal and mediational studies (see Ruiz, 2010). In particular, psychological inflexibility has been linked to lower psychosocial and physical quality of life (QoL) in IBD (Trindade et al., 2015a). Moreover, in this population, cognitive fusion was found to be a significant moderator of the relationship between physical symptomatology and depression (Trindade et al., 2015b). Given the relevance of studying the role of emotion regulation in different conditions, recent research has indicated that targeting particular content-specific domains of psychological processes in specific contexts might be of special importance (Gillanders et al., 2014). Several variations of the general measure of psychological inflexibility (AAQ; Bond et al., 2011) have been developed for specific disorders, syndromes, and diseases. For example, recent studies have constructed the Acceptance and Action Diabetes Questionnaire (AADQ; Gregg et al., 2007), the Acceptance and Action Epilepsy Questionnaire (AAEpQ; Lundgren, Dahl, \& Hayes, 2008), the Chronic Pain Acceptance Questionnaire (CPAQ; McCracken, Vowles, \& Eccleston, 2004), the Irritable Bowel Syndrome Acceptance and Action Questionnaire (IBSAAQ; Ferreira, Eugenicos, Morris, \& Gillanders, 2013), and the Chronic Illness Acceptance Questionnaire (CIAQ; 
Beacham, Linfield, Kinman, \& Payne-Murphy, 2015), among others. Nevertheless, to our knowledge, the general measure of cognitive fusion (CFQ; Gillanders et al., 2014) has yet only been adapted in two studies to specifically address body image-related cognitive fusion (CFQ-BI; Ferreira, Trindade, Duarte, \& Pinto-Gouveia, 2014) and food-craving disturbing thoughts (Duarte, Pinto-Gouveia, Ferreira, \& Silva, 2016). These measures have shown favourable and useful contributions for the body image field, presenting incremental validity over the general CFQ and the ability to distinguish cases of eating psychopathology.

In this context, it seems useful to create a specific measure of cognitive fusion related to the experience of having a chronic illness, to allow and facilitate a more adequate assessment of this emotion regulation process in individuals with any type of chronic illness. The present study therefore aims to develop the Cognitive Fusion Questionnaire-Chronic Illness (CFQ-CI) through an adaption of the CFQ-7's items (Gillanders et al., 2014) and to validate this new measure in a sample of IBD patients by performing a confirmatory factor analysis (CFA) and a series of psychometric analyses. It is expected that the scale will present a one-factorial structure such as the CFQ-7 (Gillanders et al., 2014). This study also aims to explore the meditational function (and thus construct validity) of chronic illness-related cognitive fusion (CFQ-CI) on the associations of IBD symptomatology and chronic illness-related shame with psychological QoL. According to the ACT model, it is expected that, if the measure presents good construct validity, chronic illness-related cognitive fusion will significantly mediate these associations.

\section{Material and Methods}

\section{Procedures}


This study is part of a research project aiming to analyse the role of emotion regulation in chronic illness. Patients were recruited through the Portuguese Association for IBD (APDI). Patients affiliated with this association do not have contact with each other and the association does not provide support groups. Patients that agreed to participate gave their informed consent and completed a test battery on an online platform, within approximately 25 min. All ethical standards for research with human participants were met (the study was approved by the Ethical Board of the Faculty of Psychology and Education Sciences of the University of Coimbra-CEDI2016). Participants were informed about the procedures and voluntary nature of the study, purpose and confidentiality of the provided data, and their right to abandon the study at any time.

\section{Scale Development}

The CFQ-CI was developed to assess the level of cognitive fusion specifically associated with the experience of having a chronic illness and its symptomatology. This scale was developed through the adaptation of the validated Portuguese version of the CFQ-7 (Gillanders et al., 2014; Portuguese version by Pinto-Gouveia, Dinis, Gregório, \& Pinto, 2014), whose items were modified to specifically assess chronic illness-related cognitive fusion (e.g. "I tend to get very entangled in my thoughts" to "I tend to get very entangled in my thoughts about my illness and/or symptoms"). Concerning the adaptation of the third item of the CFQ-7 ("I over-analyse situations to the point where it's unhelpful to me"), the authors chose to provide examples of situations that may arise due to a chronic illness or symptoms so the respondent would consider daily life occasions ("I over-analyse situations associated with my illness to the point where it's unhelpful to me (for example, conversations with my friends; school or work situations)"). Similarly to 
the CFQ-7, the CFQ-CI's items are measured on a 5-point Likert scale (from 0: never true to 4: always true). After the CFQ-CI was constructed, its items were analysed by Portuguese experts in ACT and Portuguese chronic patients to guarantee their adequacy; minor changes were then made to the scale.

The original CFQ-CI is thus in the Portuguese language. Nevertheless, a back translation to English was performed by the authors (native speakers of Portuguese and fluent in English) so it could be presented in this paper (Table 1). The English version of the scale was then assessed for equivalence by bilingual translators. This back translation followed the recommendations by Reynolds and Suzuki (2013) on scale translation. It is however important to note that this paper does not present the validation of this English version of the CFQ-CI.

Please insert Table 1 around here

\section{Measures}

Participants reported demographic and medical data (form of IBD, time since IBD diagnosis, frequency of IBD symptomatology during the previous month, associated medical complications, and history of surgery) and completed the Portuguese validated versions of the following instruments:

ACT Measures:

Cognitive Fusion Questionnaire-7 (CFQ-7; Gillanders et al., 2014; Portuguese Version by Pinto-Gouveia et al., 2014) 
This instrument assesses broad cognitive fusion, i.e. the degree to which participants become fused or entangled with the content of their internal experiences in general. The CFQ-7 presents 7 items (e.g. "I get so caught up in my thoughts that I am unable to do the things that I most want to do"; "I get upset with myself for having certain thoughts") that are rated on a 7-point scale (from 1: never true to 7: always true); higher scores thus reveal higher levels of cognitive fusion. The scale has shown very good internal reliabilities in its original ( $\alpha$ s between 0.88 and 0.93 across five samples) and Portuguese validation studies ( $\alpha$ s between 0.89 and 0.94 across three samples).

Acceptance and Action Questionnaire-II (AAQ-II; Bond et al., 2011; Portuguese Version by Pinto-Gouveia, Gregório, Dinis, \& Xavier, 2012)

This is a 7-item measure of experiential avoidance, the unwillingness to connect with and accept one's internal experiences such as sensations, thoughts, or emotions (e.g. "I'm afraid of my feelings"; "I worry about not being able to control my worries and feelings"). The items are evaluated using a 7-point scale (1: never true to 7: always true). The AAQ-II has presented good internal consistencies in the original (with a mean $\alpha$ of 0.84 across six different samples $)$ and Portuguese $(\alpha=0.90)$ versions.

Engaged Living Scale (ELS-9; Trompetter et al., 2013; Portuguese Version by Trindade, Ferreira, Pinto-Gouveia, \& Nooren, 2016)

The ELS was developed as a 16-item measure of the process of engaged living, as conceptualized in ACT. Items (e.g. "I believe that my values are really reflected in my behaviour"; "My emotions don't hold me back from doing what's important to me") are scored on a 5-point Likert scale (1: completely disagree; 5: completely agree) and include two factors, valued living (VL) and life fulfilment (LF). The shorter, 9-item, version of 
the scale was used in the present study. This version has revealed adequate internal reliabilities $\left(\alpha_{\mathrm{total}}=0.88 ; \alpha_{\mathrm{VL}}=0.76 ; \alpha_{\mathrm{LF}}=0.89\right.$; Trindade et al., 2016).

\section{Shame:}

Chronic Illness-Related Shame Scale (CISS; Trindade et al., 2017a)

The CISS is a 7-item measure of shame associated with the experience of having a chronic illness and/or its symptomatology. Items (e.g. "I feel that my illness is embarrassing"; "I'm ashamed of talking with others about my illness or symptoms") are rated on a 5-point Likert scale (0: never true; 4: always true). In its original study, CISS showed a very good internal reliability, with a Cronbach's alpha of 0.91 .

Rumination:

Ruminative Response Scale (RRS-10; Treynor, Gonzalez, \& Nolen-Hoeksema, 2003; Portuguese Version by Dinis, Pinto-Gouveia, Duarte, \& Castro, 2011)

The RRS-10 is a 10-item measure rated on a 4-point scale (0: almost never; 3 : almost always) that assesses the level of rumination presented by the participant when feeling sad or with other negative moods. It contains two subscales, reflective rumination (which refers to attempts to understand the reasons of the negative mood, and to problem resolution) and brooding (which comprises perseverant thoughts about the negative consequences of negative mood, and the obstacles for problem solution). In the present study, the brooding subscale was used, which has shown good reliabilities in the original $(\alpha=0.77)$ and Portuguese studies $(\alpha=0.76)$. The brooding subscale (e.g. "Think 'Why do I have problems other people don't have?"; "Think 'What am I doing to deserve 
this?"') was used given that brooding is considered the most pathological form of rumination (Watkins, 2009).

Quality of life:

World Health Organization Brief Quality of Life Assessment Scale (WHOQOLBREF; The WHOQOL Group, 1998; Portuguese Version by Canavarro et al., 2009)

The WHOQOL-BREF is a 24-item measure of subjective perceptions of QoL. Items are rated on a 5-point Likert scale (higher scores indicate perceptions of higher QoL) and are distributed over four domains_-physical health (e.g. "To what extent do you feel that physical pain prevents you from doing what you need to do?"), psychological health (e.g. "How often do you have negative feelings such as blue mood, despair, anxiety, depression?"-reverse item), social relationships (e.g. "How satisfied are you with your personal relationships?"), and environment. The scale also presents two additional items that evaluate general quality of life and general health. This instrument has demonstrated adequate internal reliabilities in its original (with $\alpha$ s varying from 0.66 to 0.84 ) and Portuguese versions (with $\alpha$ s comprised between 0.67 and 0.87 ).

The reliabilities of these instruments in the present study are reported in Table 2 . Please insert Table 2 around here

\section{Participants}

This sample included 120 Portuguese IBD patients (37 males and 83 females), with ages ranging from 19 to 77 years $(M=37.90 ; S D=11.29)$, and levels of education 
from 7 th grade to $\mathrm{PhD}\left(M_{\text {completed years of education }}=14.79 ; S D=2.71\right)$. No significant differences regarding age or years of education were found between genders (age: $t_{(55.32)}=1.44 ; p=.155 ;$ years of education: $\left.t_{(118)}=-0.53 ; p=.597\right)$. Regarding medical information, $74(61.70 \%)$ and 45 participants (37.50\%) had been diagnosed with Crohn's disease and ulcerative colitis, respectively. Time since diagnosis ranged from 1.5 to 40 years $(M=10.58 ; S D=7.44)$, and one person was still undergoing the diagnostic process. Thirty-eight (31.70\%) participants reported having history of surgery, and 35 (29.20\%) presented with one or more associated medical complications (osteoarticular problems, anaemia, and dermatological conditions were the most reported). Furthermore, 19 $(15.80 \%)$ participants stated having active disease during the time of the assessment.

\section{Statistical analyses}

The analyses of the present study were conducted using IBM SPSS Statistics 22 (IBM Corp., 2013) and the AMOS software (v. 22; Arbuckle, 2013).

A CFA was conducted to confirm whether the structure of the CFQ-CI was similar to the one presented by the original CFQ-7. This analysis was performed with Maximum Likelihood as the estimation method, due to the confirmed normality and the samples' variability (outliers were maintained). Several goodness-of-fit indices were selected to interpret the CFA results: the Comparative Fit Index (CFI), Tucker and Lewis Index (TLI), and the Incremental Fit Index (IFI) which should present values around 0.95 (Hu \& Bentler, 1999). Moreover, we also considered the Standardized Root Mean Squared Residual (SRMR), which indicates a good model fit when $<0.08$ (Hu \& Bentler, 1999). The local adjustment of the models was assessed by the items' individual reliability through the evaluation of standardized regression weights (SRW) and squared multiple 
correlations (SMC), considering acceptable values of $\mathrm{SRW} \geq 0.50$ and $\mathrm{SMC} \geq 0.25$ (Marôco, 2010).

CFQ-CI's internal reliability was assessed through Cronbach's alpha values (which indicate an excellent internal consistency when $>0.90$ ). The incremental validity of the CFQ-CI was tested by performing partial correlations with the other study variables, while controlling for CFQ-7.

Furthermore, Pearson correlation coefficients were calculated to explore CFQCI's associations with other measures. Pearson correlation coefficients were interpreted using the following effect sizes: small $(r=.10-.29)$, moderate $(r=.30-.49)$, large $(r=.50-.69)$, very large $(r=.70-.89)$, nearly perfect $(r \geq .90)$, or perfect $(r=1$; Cohen, Cohen, West, \& Aiken, 2003).

As a test of construct validity, this study also aims to analyse whether cognitive fusion related to a chronic illness mediates the relationships of IBD symptomatology and chronic illness-related shame with psychological QoL. Therefore, a path analysis was conducted using Amos software (Arbuckle, 2013) using Maximum Likelihood as the estimation method, to analyse whether chronic illness-related shame (CISS) and chronic illness-related cognitive fusion (CFQ-CI) would be significant mediators of the known association between IBD symptomatology and psychological QoL, while controlling for IBD-related associated medical complications and age. Path analysis is a type of structural equation modelling (SEM) that analyses structural associations and direct and indirect paths (Schumacker \& Lomax, 2004). This analysis was conducted using the bootstrap procedure (with 5000 samples) to create $95 \%$ bias-corrected confidence intervals around the standardized estimates of total, direct and indirect effects. If the interval between the lower and the upper bounds of the $95 \%$ bias-corrected confidence interval (95\% CI) does not include zero, the effects are statistically significant (Kline, 2005). The adjustment of 
the tested model to the empirical data was examined using the goodness-of-fit indices previously described.

\section{Results}

\section{Preliminary Analysis}

Skewness and Kurtosis values showed that the study variables did not deviate significantly from a normal distribution (Skewness varied between -0.45 and 1.52 , and Kurtosis between -0.37 and 2.65). Further, visual inspection of distributions corroborated the assumption of normality (Kline, 2005).

\section{Confirmatory Factor Analysis of the CFQ-CI}

The CFQ-CI's structure was confirmed through a CFA. Results indicated that the model provided a very good fit to the empirical data: $\mathrm{CFI}=0.97 ; \mathrm{TLI}=0.94 ; \mathrm{IFI}=0.96$; SRMS $=0.03$. Furthermore, the local adjustment of the model was also good (Table 1), with SRWs varying between 0.81 (item 3) and 0.95 (items 4 and 7) and SMCs between 0.65 (item 3) and 0.91 (item 7).

\section{Reliability}

The CFQ-CI had excellent internal consistency, with a Cronbach's alpha of 0.97. Results also revealed that the inter-item correlations were strong and the deletion of any item would not improve internal consistency (see Table 1).

\section{Construct validity}

The CFQ-CI's convergent validity was further analysed through the estimation of zero-order correlations between the CFQ-CI and other measures. In addition, partial 
correlations were conducted controlling for general cognitive fusion, as measured by the CFQ-7.

As shown in Table 2, the CFQ-CI presented positive and high correlations with the measure of general cognitive fusion (CFQ-7), psychological inflexibility (AAQ-II), brooding (RRS-10), and shame related to chronic illness (CISS). The CFQ-CI also presented positive and moderate associations with IBD symptomatology. Moreover, the CFQ-CI was negative and moderately linked to engaged living (ELS-9), general QoL, and physical QoL (WHOBREF). Finally, a negative and strong correlation between CFQCI and psychological QoL was also found.

Results from the partial correlations controlling for the CFQ-7 showed that most of the CFQ-CI's correlations with the other measures remained significant (Table 2), thus demonstrating CFQ-CI's incremental validity. Further, two regression analyses were conducted having CFQ-7 as a sole predictor of the outcomes on the first step of the analyses and then adding CFQ-CI as a predictor of the regression model. Regarding psychological QoL as an outcome, the results demonstrated that CFQ-7 explained $45 \%$ of the variance of psychological QoL (with an effect of $\beta=-0.68 ; p<.001$ ). When CFQCI was added to the model, the explained variance of psychological QoL increased to $51 \%$, and both predictors were significant (CFQ-7: $\beta=-0.46 ; p<.001 ; \mathrm{CFQ}-\mathrm{CI}$ : $\beta=-0.31 ; p=.001)$. Concerning physical QoL, CFQ-7 alone accounted for $11 \%$ of the variance of the outcome $(\beta=-.34 ; p<.001)$. When CFQ-CI was added to this model, the explained variance of physical QoL increased to $15 \%$ and CFQ-CI became the only significant predictor of the model (CFQ-7: $\beta=-0.16 ; p=.172 ; \mathrm{CFQ}-\mathrm{CI}: \beta=-.26$; $p=.029)$. 
The Mediator Role of Chronic Illness-Related Cognitive Fusion in the Relationship Between IBD Symptomatology and Psychological QoL (Construct Validity of the CFQ-CI)

Considering the significant associations between IBD symptoms, chronic illnessrelated shame, cognitive fusion associated with chronic illness, and psychological QoL (Table 3), a path model was tested to examine whether chronic illness-related cognitive fusion would mediate the associations of IBD symptomatology and chronic illness-related shame with psychological QoL.

Please insert Table 3 around here

The tested theoretical model (Fig. 1) presented 34 parameters and explained 15\% of CISS, 52\% of CFQ-CI, and 44\% of the variance of psychological QoL. The model presented an excellent fit to the empirical data, with the following goodness-of-fit indices: $\mathrm{CFI}=0.99 ; \mathrm{TLI}=0.97 ; \mathrm{IFI}=0.99 ; \mathrm{GFI}=0.97 ; \mathrm{SMRS}=0.07$. Moreover, all individual path coefficients were statistically significant.

Please insert Figure 1 around here

IBD symptomatology directly predicted CISS with an effect size of 0.39 $\left(b_{\text {IBDsymptoms }}=0.20 ; \mathrm{SE}=0.04 ; Z=4.67 ; p<.001\right)$. Through the mechanisms ofCISS, IBD symptomatology also predicted CFQ-CI with an indirect effect of 0.28 (95\% CI $0.15-$ $0.41 ; p<.001)$. Furthermore, IBD symptomatology indirectly predicted psychological QoL with an effect of -0.24 , mediated by CISS and CFQ-CI (95\% CI -0.35 to -0.12 ; $p<.001)$ 
CISS directly predicted CFQ-CI with an effect of $0.72\left(b_{\text {CISS }}=1.10 ; \mathrm{SE}=0.10\right.$; $Z=11.27 ; p<.001)$. Further, CISS presented a significant effect on psychological QoL with a total effect of -0.61 : a direct effect of $-0.32\left(b_{\mathrm{CISS}}=-0.79 ; \mathrm{SE}=0.24 ; Z=-3.25\right.$; $p<.01)$ and an indirect effect of -0.29 significantly mediated by the mechanisms of CFQ-CI $(95 \%$ CI -0.46 to $-0.15 ; p<.001)$. CFQ-CI, in turn, directly predicted psychological QoL with an effect of $-0.40\left(b_{\mathrm{CFQ}-\mathrm{CI}}=-0.64 ; \mathrm{SE}=0.16 ; Z=-4.06\right.$; $p<.001)$.

In summary, as IBD symptomatology increases, patients are more likely to feel shame for their condition, which decreases their psychological QoL. Further, feelings of shame related to a chronic illness seem to lead to increased fusion with illness-related thoughts, which partially explains the effects of illness-related shame on psychological QoL.

\section{Discussion}

The current study presents the development and preliminary validation of the CFQ-CI, a scale adapted from the general measure of cognitive fusion, the CFQ-7 (Gillanders et al., 2014; Pinto-Gouveia et al., 2014), to specifically measure fusion with thoughts related to the experience of having a chronic illness and symptomatology.

A CFA was performed to confirm the unidimensional 7-item structure of the CFQCI, using a sample of IBD patients. The global adjustment of the scale to the empirical data was excellent (Hu \& Bentler, 1999). Furthermore, the local fit of the CFQ-CI was also good, with individual fit indices above the recommended cut-offs (Marôco, 2010; Tabachnick \& Fidell, 2013).

The CFQ-CI was also shown to have an excellent internal reliability $(\alpha=0.97)$ which would not be improved with the deletion of any item. Furthermore, the CFQ-CI 
was linked to other instruments in the expected directions. It was positively associated with the measures of general cognitive fusion (CFQ-7) and psychological inflexibility (AAQ-II), going in line with ACT's conceptualizations of cognitive fusion as a central process of psychological inflexibility (e.g. Hayes et al., 2012). The CFQ-CI also presented positive correlations with chronic illness-related shame (CISS) and brooding (RRS-10). In this way, these results show that fusion with thoughts related to a chronic illness are linked to higher levels of shame related to the disease and to higher tendencies to ruminate about the consequences of negative mood and the obstacles to problem solving (i.e. to increased levels of brooding). On the other hand, the CFQ-CI was negatively linked to engaged living (ELS-9), indicating that getting entangled with thoughts about a chronic illness is related to lower engagement in behaviours committed to one's values. Moreover, the results also demonstrated that chronic illness-related cognitive fusion was associated with lower general, psychological, and even physical well-being.

The incremental validity of the CFQ-CI in relation to the CFQ-7 was tested for every studied variable. This analysis showed that the CFQ-CI presented incremental validity for all variables, except ELS-9. These data warrant attention from future studies since it may translate an unfavourable feature of the CFQ-CI or may indicate that, in relation to the ELS-9 and in samples of chronic patients, CFQ-7 and CFQ-CI behave similarly. The incremental power of CFQ-CI over CFQ-7 was also tested through regression analyses. It was revealed that the explained variance of both psychological QoL and physical QoL increased when CFQ-CI was added to the model, which demonstrates that this measure adds information (over CFQ-7) to the prediction of these outcomes. Regarding physical QoL, it is also noteworthy to mention that CFQ-7's predictive effect lost significance when CFQ-CI was added to the model. This expected 
result indicates that the measure of cognitive fusion specifically related to the experience of having a chronic illness is a better predictor of the physical dimension of QoL. These findings corroborate the incremental power of CFQ-CI over a measure of general cognitive fusion.

Scores on the CFQ-CI thus appear to be reliable and valid measures of fusion with thoughts relating to a chronic health condition. These thoughts may certainly vary due to individual differences, the context, and the characteristics of the disease in question. Findings from the path model tested in the current study, which indicate that the scale might present construct validity, may also suggest that shame feelings derived from the experience of IBD symptomatology can lead to entanglement with thoughts related to chronic illness, probably unwanted and difficult thoughts such as "these symptoms are so embarrassing", "no one understands my condition", or "my illness is only going to get worse". This model corroborates ACTs theory (e.g. Hayes et al., 2012) by suggesting that fusion with thoughts like these seems to be linked to lower levels of psychological wellbeing and mediate the association between shame feelings and this outcome. This finding might be explained by the dominance of verbal content related to the illness and consequent overthinking and lack of action consistent with the context and the patient's life values (Gillanders et al., 2014). Patients may, in a matter of fact, respond to chronic illness-related cognitive fusion by avoiding or trying to control situations or physical sensations. For example, if an IBD patient tends to believe thoughts such as "my intestinal symptoms are too embarrassing" or "others will know I have a problem and will think less of me", he or she may choose to deal with these internal experiences by avoiding social contexts. Furthermore, getting entangled with the thought "This cramp is too much to bear" may lead to attempts to suppress physical pain, which might only aggravate it (e.g. Cioffi \& Holloway, 1993). The mechanisms that influence the relationship between 
chronic illness-related shame and QoL should, nevertheless, be further examined in future studies.

Given that this study only comprises a sample of 120 Portuguese IBD patients, future studies should try to replicate these findings as well as analyse CFQ-CI's psychometric qualities in other chronic illnesses and languages/cultures, using larger samples. Furthermore, sample recruitment might also be a limitation to the current study, making the sample exclusively composed of patients that are affiliated with an association and have access to the internet and aptitude to fill an online survey. The CFQ-CI should thus be further studied in patients recruited in medical settings. Furthermore, the scale's associations with psychopathology ought to also be explored, as well as its sensitivity to change in interventions targeting cognitive fusion in chronic patients. CFQ-CI's discriminant validity ought to also be tested in future studies. Finally, due to the crosssectional nature of this study, the interpretation of the tested model should be cautious and noncausal. Longitudinal designs would be required to establish causality between the studied relationships.

Overall, the CFQ-CI is a short and psychometrically robust scale that can be used in the context of any chronic illness, with the advantage of specifically assessing chronic illness-related cognitive fusion. Further, this construct seems to be an important process for the determination of chronic patients' mental well-being. The creation of a specific measure of chronic illness-related cognitive fusion may thus contribute to a better understanding of the mechanisms influencing functional outcomes in chronic illness.

\section{Acknowledgements}

We are grateful for the help provided by the Portuguese Association for IBD (Associação Portuguesa para a Doença Inflamatória do Intestino; APDI) during the recruitment 
process of the current research project. We would also like to thank the Editor and Reviewers of this manuscript for their input and help in improving the manuscript.

\section{Funding}

This research has been supported by the first author (Inês A. Trindade), PhD Grant (SFRH/BD/101906/2014) sponsored by FCT (Portuguese Foundation for Science and Technology).

\section{Compliance with Ethical Standards}

Conflict of interest

Inês A. Trindade, Cláudia Ferreira, and José Pinto-Gouveia declare that they have no conflict of interest.

Human and Animal Rights

All procedures were in accordance with the ethical standards of the institutional research committees and with the 1964 Helsinki declaration and its later amendments or comparable ethical standards.

Informed Consent

Informed consent was obtained from all individual participants included in the study. 


\section{References}

Arbuckle, J. L. (2013). Amos 22.0 User's Guide. Chicago: IBM SPSS.

Beacham, A. O., Linfield, K., Kinman, C. R., \& Payne-Murphy, J. (2015). The chronic illness acceptance questionnaire: Confirmatory factor analysis and prediction of perceived disability in an online chronic illness support group sample. Journal of Contextual Behavioral $\quad$ Science, $\quad 4(2), \quad 96-$ 102. https://doi.org/10.1016/j.jcbs.2015.03.001.

Bond, F. W., Hayes, S. C., Baer, R. A., Carpenter, K. M., Guenole, N., Orcutt, H. K., ... Zettle, R. (2011). Preliminary psychometric properties of the Acceptance and Action Questionnaire-II: A revised measure of psychological inflexibility and experiential avoidance. Behavior Therapy, 42, 676688. https://doi.org/10.1016/j.beth.2011.03.007.

Branstetter, A. D., Wislon, K. G., Hildebrandt, M., \& Mutch, D. (2004). Improving psychological adjustment among cancer patients: ACT and CBT. Paper presented at the meeting of the Association for Advancement of Behavior Therapy, New Orleans.

Canavarro, M. C., Serra, A. V., Simoes, M. R., Rijo, D., Pereira, M., Gameiro, S., ... Paredes, T. (2009). Development and psychometric properties of the World Health Organization Quality of Life Assessment Instrument (WHOQOL-100) in Portugal. International Journal of Behavioral Medicine, 16(2), 116124. https://doi.org/10.1007/s12529-008-9024-2.

Cioffi, D., \& Holloway, J. (1993). Delayed costs of suppressed pain. Journal of Personality and Social Psychology, 64(2), 274-282. https://doi.org/10.1037/00223514.64.2.274. 
Clarke, D. M., \& Currie, K. C. (2009). Depression, anxiety and their relationship with chronic diseases: A review of the epidemiology, risk and treatment evidence. The Medical Journal of Australia, 190(7 Suppl), S54-S60.

Cohen, J., Cohen, P., West, S. G., \& Aiken, L. S. (2003). Applied multiple regression/correlation analysis for the behavioral sciences. Hillsdale: ErlbaumGoogle Scholar

Dinis, A., Pinto-Gouveia, J., Duarte, C., \& Castro, T. (2011). Estudo de validação da versão portuguesa da Escala de Respostas Ruminativas [Study of the Portuguese validation of the Ruminative Responses Scale]. Psychologica, 54, 175-202.

Duarte, C., Pinto-Gouveia, J., Ferreira, C., \& Silva, B. (2016). Caught in the struggle with food craving: Development and validation of a new cognitive fusion measure. Appetite. https://doi.org/10.1016/j.appet.2016.03.004.

Ferreira, C., Trindade, I. A., Duarte, C., \& Pinto-Gouveia, J. (2014). Getting entangled with body image: Development and validation of a new measure. Psychology and Psychotherapy: Theory, Research and Practice. https://doi.org/10.1111/papt.12047.

Ferreira, N. B., Eugenicos, M. P., Morris, P. G., \& Gillanders, D. T. (2013). Measuring acceptance in irritable bowel syndrome: Preliminary validation of an adapted scale and construct utility. Quality of Life Research, 22(7), 17611766. https://doi.org/10.1007/s11136-012-0299-z.

Gerteis, J., Izrael, D., Deitz, D., LeRoy, L., Ricciardi, R., Miller, T., \& Basu, J. (2014). Multiple chronic conditions chartbook (AHRQ Publications No. Q14-0038). Rockville, MD: Agency for Healthcare Research and Quality.

Gillanders, D. T., Bolderston, H., Bond, F. W., Dempster, M., Flaxman, P. E., Campbell, L., ... Remington, B. (2014). The development and initial validation of the 
Cognitive Fusion Questionnaire. Behavior Therapy, 45(1), 83101. https://doi.org/10.1016/j.beth.2013.09.001.

Graff, L. A., Walker, J. R., Lix, L., Clara, I., Rawsthorne, P., Rogala, L., ... Bernstein, C. N. (2006). The relationship of inflammatory bowel disease type and activity to psychological functioning and quality of life. Clinical Gastroenterology and Hepatology: The Official Clinical Practice Journal of the American Gastroenterological Association, $\quad 4(12), \quad 1491-$ 1501. https://doi.org/10.1016/j.cgh.2006.09.027.

Gregg, J. A., Callaghan, G. M., Hayes, S. C., \& Glenn-Lawson, J. L. (2007). Improving diabetes self-management through acceptance, mindfulness, and values: A randomized controlled trial. Journal of Consulting and Clinical Psychology, 75(2), 336-343. https://doi.org/10.1037/0022-006X.75.2.336.

Hadlandsmyth, K., White, K. S., Nesin, A. E., \& Greco, L. A. (2013). Proposing an Acceptance and Commitment Therapy intervention to promote improved diabetes management in adolescents: A treatment conceptualization. International Journal of Behavioral Consultation and Therapy, 7(4), 1215. https://doi.org/10.1037/h0100960.

Hayes, S. C., Luoma, J. B., Bond, F., Masuda, A., \& Lillis, J. (2006). Acceptance and commitment therapy: Model, processes and outcomes. Behaviour Research and Therapy, 44, 1-25. https://doi.org/10.1016/j.brat.2005.06.006.

Hayes, S. C., Strosahl, K. D., \& Wilson, K. G. (2012). Acceptance and commitment therapy: The process and practice of mindful change (2nd ed.). New York: Guilford Press.

Hu, L., \& Bentler, P. M. (1999). Cutoff criteria for fit indexes in covariance structure analysis: Conventional criteria versus new alternatives. Structural Equation 
Modeling: $\quad$ A $\quad$ Multidisciplinary $\quad$ Journal, $\quad 6(1), \quad 1-$

55. https://doi.org/10.1080/10705519909540118.

IBM Corp. (2013). IBM SPSS Statistics for Windows, Version 22.0 [computer software]. Armonk, NY: IBM Corp.

Kline, R. B. (2005). Principles and practice of structural equation modeling (2nd ed.). New York: Guilford Press.

Levenstein, S. (2004). Embracing complexity: What determines quality of life in inflammatory bowel disease? European Journal of Gastroenterology \& Hepatology, 16(12), 1253-1255. https://doi.org/10.1097/00042737-20041200000002.

Lundgren, T., Dahl, J., \& Hayes, S. C. (2008). Evaluation of mediators of change in the treatment of epilepsy with acceptance and commitment therapy. Journal of Behavioral Medicine, 31(3), 225-235. doi: 10.1007/s10865-008-9151-x

Lundgren, T., Dahl, J., Melin, L., \& Kies, B. (2006). Evaluation of acceptance and commitment therapy for drug refractory epilepsy: A randomized controlled trial in South Africa - A pilot study. Epilepsia, 47(12), 21732179. https://doi.org/10.1111/j.1528-1167.2006.00892.x.

Marôco, J. (2010) Análise de Equações Estruturais: Fundamentos teóricos, software e aplicações [Analysis of structural equations: Theoretical foundations, software and applications]. Pero Pinheiro: Report Number.

McCracken, L. (2011). History context and new developments in behavioral medicine. In L. McCracken (Ed.), Mindfulness and acceptance in behavioral medicine: Current theory and practice (pp. 3-30). Oakland, CA: New Harbinger. 
McCracken, L. M., Vowles, K. E., \& Eccleston, C. (2004). Acceptance of chronic pain: Component analysis and a revised assessment method. Pain, 107(1), 159166. https://doi.org/10.1016/j.pain.2003.10.012.

Pinto-Gouveia, J., Dinis, A., Gregório, S., \& Pinto, A. (2014). The Preliminary psychometric properties of the portuguese version of the cognitive fusion questionnaire (manuscript in preparation).

Pinto-Gouveia, J., Gregório, S., Dinis, A., \& Xavier, A. (2012). Experiential avoidance in clinical and nonclinical samples. International Journal of Psychology and Psychological Therapy, 12(2), 139-156.

Reynolds, C. R., \& Suzuki, L. (2013). Bias in psychological assessment: An empirical review and recommendations. In J. R. Graham, J. A. Naglieri, \& I. B. Weiner (Eds.), Handbook of psychology (Vol. 10). Assessment psychology (2nd ed., pp. 82-113). Hoboken, NJ: Wiley.

Ruiz, F. J. (2010). A review of acceptance and commitment therapy (ACT) empirical evidence: Correlational, experimental psychopathology, component and outcome studies. International Journal of Psychology and Psychological Therapy, 10(1), 125-162. https://doi.org/10.1080/028457199439937.

Schumacker, R. E., \& Lomax, R. G. (2004). A beginner's guide to structural equation modeling (2nd ed.). Mahwah, NJ: Lawrence Erlbaum Associates.

Segal, Z. V., Williams, J. M. G., \& Teasdale, J. D. (2002). Mindfulness-based cognitive therapy for depression: A new approach to preventing relapse. New York: Guilford Press.

Tabachnick, B., \& Fidell, L. (2013). Using multivariate statistics (6th ed.). Boston: Pearson. 
The WHOQOL Group. (1998). The World Health Organization Quality of Life Assessment (WHOQOL): Development and general psychometric properties. Social Science \& Medicine, 46, 1569-1585. https://doi.org/10.1016/S02779536(98)00009-4.

Treynor, W., Gonzalez, R., \& Nolen-Hoeksema, S. (2003). Rumination reconsidered: A psychometric analysis. Cognitive Therapy and Research, 27(3), 247259. https://doi.org/10.1023/A:1023910315561.

Trindade, I. A., Ferreira, C., \& Pinto-Gouveia, J. (2015a). Inflammatory bowel disease: The harmful mechanism of experiential avoidance for patients' quality of life. Journal of Health Psychology. https://doi.org/10.1177/1359105315587142.

Trindade, I. A., Ferreira, C., \& Pinto-Gouveia, J. (2015b). Ulcerative colitis symptomatology and depression: The exacerbator role of maladaptive psychological processes. Digestive Diseases and Sciences, 60(12), 37563763. https://doi.org/10.1007/s10620-015-3786-6.

Trindade, I. A., Ferreira, C., \& Pinto-Gouveia, J. (2017a). Chronic illness-related shame: Development of a new scale and novel approach for IBD patients' depressive symptomatology. Clinical Psychology and Psychotherapy, 24(1), 255263. https://doi.org/10.1002/cpp.2035.

Trindade, I. A., Ferreira, C., \& Pinto-Gouveia, J. (2017b). Shame and emotion regulation in inflammatory bowel disease: Effects on psychosocial functioning. Journal of Health Psychology. https://doi.org/10.1177/1359105317718925.

Trindade, I. A., Ferreira, C., Pinto-Gouveia, J., \& Nooren, L. (2016). Clarity of personal values and committed action: Development of a shorter Engaged Living Scale. Journal of Psychopathology and Behavior Assesment. https://doi.org/10.1007/s10862-015-9509-7. 
Trompetter, H. R., ten Klooster, P. M., Schreurs, K. M. G., Fledderus, M., Westerhof, G. J., \& Bohlmeijer, E. T. (2013). Measuring values and committed action with the Engaged Living Scale (ELS): Psychometric evaluation in a nonclinical and chronic pain sample. Psychological Assessment, 25(4), 12351246. https://doi.org/10.1037/a0033813.

Vlaeyen, J. W., \& Linton, S. J. (2000). Fear-avoidance and its consequences in chronic musculoskeletal pain: A state of the art. Pain, 85(3), 317332. https://doi.org/10.1016/s0304-3959(99)00242-0.

Vowles, K. E., \& McCracken, L. M. (2008). Acceptance and values-based action in chronic pain: A study of treatment effectiveness and process. Journal of Consulting and Clinical Psychology, 76(3), 397-407. https://doi.org/10.1037/0022006x.76.3.397.

Ward, B. W., Schiller, J. S., \& Goodman, R. A. (2014). Multiple chronic conditions among US adults: A 2012 update. Preventing Chronic Disease, 11, E62. https://doi.org/10.5888/pcd11.130389.

Watkins, E. R. (2009). Depressive rumination and co-morbidity: Evidence for brooding as a transdiagnostic process. Journal of Rational-Emotive and Cognitive-Behavior Therapy, 27(3), 160-175. https://doi.org/10.1007/s10942-009-0098-9 


\section{Table 1}

CFQ-CI's Means $(M)$, Standard deviations $(S D)$, Factor loadings $(\lambda)$, communalities $\left(h^{2}\right)$, itemtotal correlation and Cronbach's alpha $(\alpha)$ if item deleted, Standardized regression weights (SRW) and Squared Multiple Correlations $(\mathrm{SMC})(N=120)$

\begin{tabular}{|c|c|c|c|c|c|c|c|c|}
\hline Items & $M$ & $S D$ & $\lambda$ & $h^{2}$ & $\begin{array}{l}\text { Item total } \\
\text { correlation }\end{array}$ & $\begin{array}{l}\alpha \text { if item } \\
\text { deleted }\end{array}$ & SRW & SMC \\
\hline $\begin{array}{l}\text { 1. My thoughts about my illness cause me } \\
\text { distress or emotional pain }\end{array}$ & 2.88 & 1.46 & .85 & .73 & .84 & .97 & .84 & .92 \\
\hline $\begin{array}{l}\text { 2. I get so caught up in thoughts about my } \\
\text { illness that I am unable to do the things that I } \\
\text { most want to do }\end{array}$ & 2.48 & 1.42 & .93 & .86 & .92 & .96 & .91 & .89 \\
\hline $\begin{array}{l}\text { 3. I over-analyse situations associated with } \\
\text { my illness to the point where it's unhelpful to } \\
\text { me (for example, conversations with my } \\
\text { friends; school or work situations) }\end{array}$ & 2.46 & 1.52 & .81 & .65 & .79 & .97 & .79 & .79 \\
\hline $\begin{array}{l}\text { 4. I struggle with my thoughts about my } \\
\text { illness and/or symptoms }\end{array}$ & 2.37 & 1.49 & .95 & .90 & .93 & .96 & .95 & .90 \\
\hline $\begin{array}{l}\text { 5. I get upset with myself for having certain } \\
\text { thoughts about my illness. }\end{array}$ & 2.67 & 1.59 & .88 & .78 & .86 & .96 & .89 & .63 \\
\hline $\begin{array}{l}\text { 6. I tend to get very entangled in my thoughts } \\
\text { relating to my illness and/or symptoms }\end{array}$ & 2.44 & 1.51 & .94 & .88 & .92 & .96 & .94 & .83 \\
\hline $\begin{array}{l}\text { 7. It's such a struggle to let go of upsetting } \\
\text { thoughts about my illness, even when I know } \\
\text { that letting go would be helpful }\end{array}$ & 2.42 & 1.48 & .95 & .91 & .93 & .96 & .96 & .70 \\
\hline
\end{tabular}




\section{Table 2}

Zero-Order and Partial Correlations between the CFQ-CI and other measures, and their respective Cronbach's Alphas $(N=120)$.

\begin{tabular}{lccc}
\hline & & \multicolumn{2}{c}{ CFQ-CI } \\
\cline { 3 - 4 } \multicolumn{1}{c}{ Measures } & $\alpha$ & Zero-order & Partial correlation \\
& & correlation & (controlling for \\
& & & CFQ-7) \\
\hline CFQ-7 & .98 & $.68^{* * *}$ & - \\
AAQ-II & .95 & $.72^{* * *}$ & $.33^{* * *}$ \\
RRS-10 - Brooding & .84 & $.62^{* * *}$ & $.30^{* *}$ \\
IBD symptoms & .89 & $.30^{* * *}$ & $.52^{* * *}$ \\
CISS & .92 & $.72^{* * *}$ & $.26 * *$ \\
ELS-9 & .88 & $-.47^{* * *}$ & -.16 \\
General QoL & - & $-.40^{* * *}$ & $-.29^{* *}$ \\
Physical QoL & .86 & $.37^{* * *}$ & $-.20^{* *}$ \\
Psychological QoL & .83 & $-.63^{* * *}$ & $-.31^{* *}$ \\
\hline
\end{tabular}

Note. CFQ-CI $=$ Cognitive Fusion Questionnaire - Chronic Illness; CFQ-7 $=$ Cognitive Fusion Questionnaire; $\mathrm{AAQ}-\mathrm{II}=$ Acceptance and Action Questionnaire; RRQ-10 = Ruminative Responses Questionnaire; CISS = Chronic illness-related shame scale; DASS depression, DASS anxiety, and DASS stress $=$ scales of the Depression, Anxiety and Stress Scales; ELS-9 = Engaged Living Scale; General, Physical and Psychological QoL = domains of the World Health Organization Brief Quality of Life Assessment Scale (WHOQOL-BREF).

$* p<.05 ; * * p<.01 ; * * * p<.001$ 
Table 3

Means (M), Standard Deviations (SD), and intercorrelation scores of the study variables $(N=120)$

\begin{tabular}{|c|c|c|c|c|c|}
\hline & $M$ & $S D$ & 1 & 2 & 3 \\
\hline 1. IBD symptoms & 24.26 & 12.32 & - & & \\
\hline 2. Chronic illness-related shame & 8.37 & 6.26 & $.39 * * *$ & - & \\
\hline $\begin{array}{l}\text { 3. Chronic illness-related cognitive } \\
\text { fusion }\end{array}$ & 17.71 & 9.58 & $.30 * *$ & $.72 * * *$ & - \\
\hline 4. Psychological quality of life & 66.25 & 15.45 & $\begin{array}{c}- \\
.34 * * * \\
\end{array}$ & $\begin{array}{c}- \\
.61 * * * \\
\end{array}$ & $\begin{array}{c}- \\
.63 * * * \\
\end{array}$ \\
\hline
\end{tabular}

Note: ${ }^{* *} p<0.01 ;{ }^{* * *} p<0.001$. 


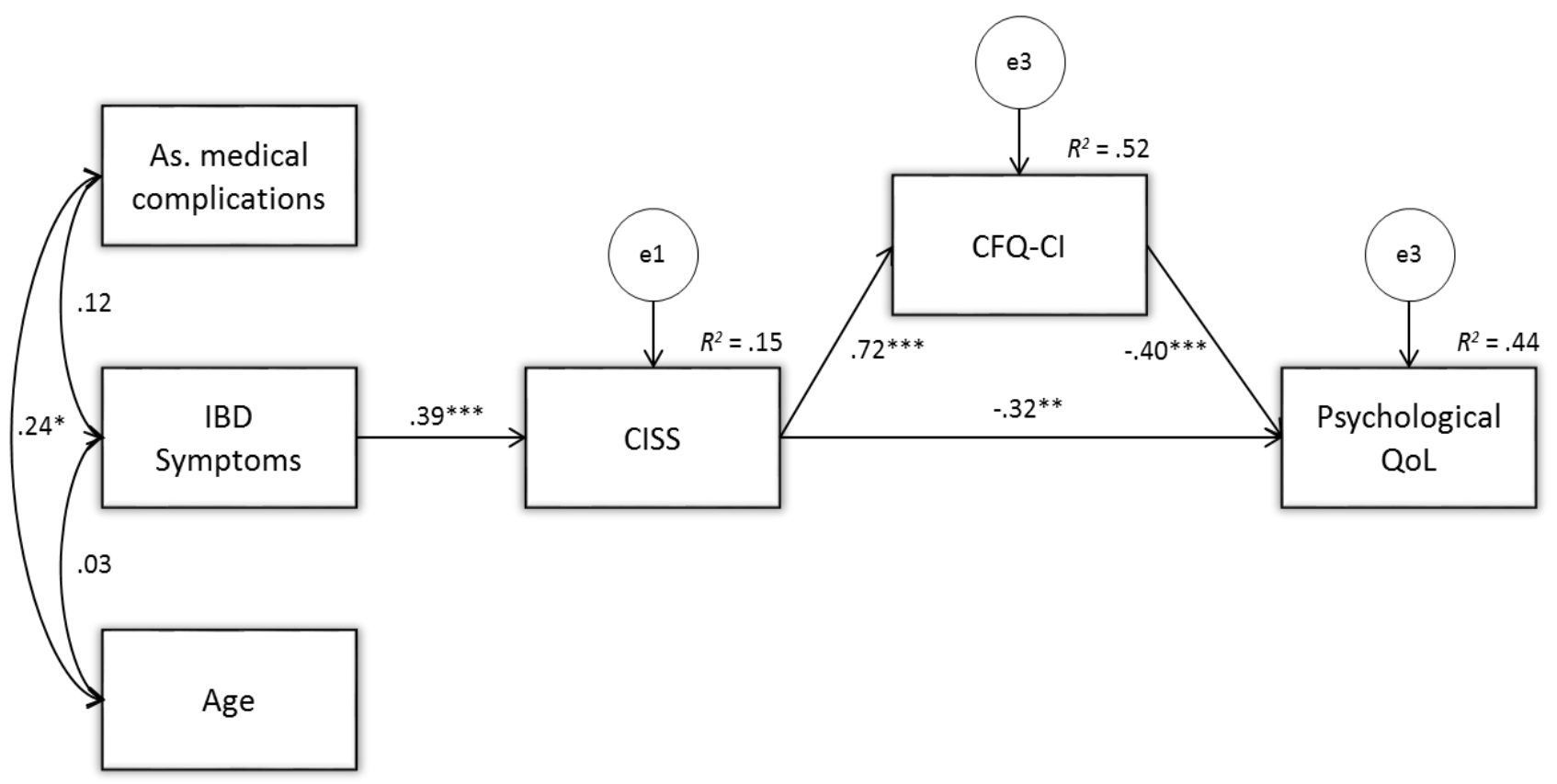

Note. Standardized path coefficients among variables are presented.

${ }^{*} p<0.05 ;{ }^{* *} p<0.01 ;{ }^{* * *} p<0.001$.

As. medical complications $=$ presence of IBD-related medical complications; CISS $=$ Chronic Illness-related Shame Scale; CFQ-CI = Cognitive Fusion Questionnaire - Chronic Illness; Psychological Health QoL= subscale of the WHOQOL-BREF. 


\section{Appendix 1. Portuguese version of the CFQ-CI}

\section{CFQ-CI}

Instruções: Em baixo, encontrará uma lista de afirmações. Por favor, classifique o quanto é verdadeira para si cada afirmação, rodeando para esse efeito um dos números que se encontra em frente a cada frase.

Responda, por favor, a cada frase, usando a seguinte escala.

\begin{tabular}{ccccccc}
\hline $\begin{array}{c}\text { Nunca } \\
\text { verdadeiro }\end{array}$ & $\begin{array}{c}\text { Muito } \\
\text { raramente } \\
\text { verdadeiro }\end{array}$ & $\begin{array}{c}\text { Raramente } \\
\text { verdadeiro }\end{array}$ & $\begin{array}{c}\text { Às vezes } \\
\text { verdadeiro }\end{array}$ & $\begin{array}{c}\text { Frequentemente } \\
\text { verdadeiro }\end{array}$ & $\begin{array}{c}\text { Quase sempre } \\
\text { verdadeiro }\end{array}$ & $\begin{array}{c}\text { Sempre } \\
\text { verdadeiro }\end{array}$ \\
\hline 1 & 2 & 3 & 4 & 5 & 6 \\
\hline
\end{tabular}

1. Os meus pensamentos em relação à minha doença perturbam-me ou causam-me sofrimento emocional.

2. Fico tão enredado/ a ("preso/a") nos meus pensamentos em relação à minha doença que me torno incapaz de fazer as coisas que eu mais quero fazer.

$\begin{array}{lllllll}1 & 2 & 3 & 4 & 5 & 6 & 7\end{array}$

3. Analiso em excesso as situações associadas com a minha doença, até ao ponto em que isso já não é útil para mim (por exemplo, conversas com os meus amigos, situações $\quad \begin{array}{lllllll}1 & 2 & 3 & 4 & 5 & 6 & 7\end{array}$ académicas ou no trabalho).

4. Vivo numa luta com os meus pensamentos acerca da minha doença e/ou sintomas. $\quad \begin{array}{rrrrrrr}1 & 2 & 3 & 4 & 5 & 6 & 7\end{array}$

5. Fico chateado/a comigo mesmo/a por ter certos pensamentos em relação à minha

$\begin{array}{llllllll}1 & 2 & 3 & 4 & 5 & 6 & 7\end{array}$ doença.

6. Tendo a deixar-me enredar ("prender") pelos meus pensamentos sobre a minha doença e/ou sintomas. minha doença, mesmo quando sei que seria mais vantajoso fazê-lo. 